\title{
Outcome of Humeral Shaft Infected Non-Unions, Treated with Orthofix External Fixator
}

\author{
Santhosh Kumar G. ${ }^{1}$, Manasseh Nithyananth ${ }^{2}$, Sandeep Albert ${ }^{3}$, Jeremy Bliss ${ }^{4}$ \\ ${ }^{1}$ Assistant Professor, Department of Orthopaedics, Christian Medical College and Hospital, Vellore, Tamilnadu, India. \\ ${ }^{2}$ Professor, Department of Orthopaedics, Christian Medical College and Hospital, Vellore, Tamilnadu, India. \\ ${ }^{3}$ Associate Professor, Department of Orthopaedics, Christian Medical College and Hospital, Vellore, Tamilnadu, India. \\ ${ }^{4}$ Assistant Professor, Department of Orthopaedics, Christian Medical College and Hospital, Vellore, Tamilnadu, India.
}

\section{ABSTRACT}

\section{BACKGROUND}

We wanted to review the infected non-unions of humeral shaft treated with Orthofix external fixators with regard to bone grafting, union, complications and resolution of infection.

\section{METHODS}

Eight men and two women with infected non-unions of humeral shaft were treated between 2003 and 2011. All patients had active pus discharge. Four injuries were closed, and the rest were open injuries. Six had internal fixation, two had external fixators and two patients had debridement during the initial treatment. The average time duration between injury and presentation was 7 months (range, 1-30). All patients underwent debridement and stabilisation with Orthofix fixator.

\section{RESULTS}

The mean follow-up was 26 months (range, 3-72). The fracture healed successfully in all patients. The average time to union was 4 months (range, 2-6). Seven patients had secondary bone grafting. One patient had revision surgery with internal fixation and bone grafting for failure of Orthofix external fixation. All patients had resolution of infection. The complications seen were pin tract infections in four patients and shoulder stiffness in two patients.

\section{CONCLUSIONS}

Infected non-unions of humeral shaft can be successfully treated with debridement and skeletal stabilisation using Orthofix external fixator. Bone grafting augments fracture healing. Resolution of infection can be achieved.

\section{KEY WORDS}

Infected Non-Union of Humerus, Non-Union, Osteomyelitis, Bone Grafting, Resolution of Infection
Corresponding Author: Dr. Santhosh Kumar G. No. 12, $5^{\text {th }}$ Cross Street, Kamban Nagar, Reddiarpalayam, Puducherry-605010, India.

E-mail:dr. santhoshgovind@gmail.com

DOI: $10.14260 /$ jemds/2019/644

Financial or Other Competing Interests: None.

How to Cite This Article: Kumar SG, Nithyananth $M$, Albert $S$, et al Outcome of humeral shaft infected nonunions, treated with orthofix external fixator. J. Evolution Med. Dent. Sci. 2019;8(39):2963-2966, 10.14260/jemds/2019/644

Submission 01-08-2019,

Peer Review 11-09-2019,

Acceptance 17-09-2019,

Published 30-09-2019.

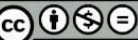




\section{BACKGROUND}

Infected non-union of humerus is not common. Literature is also sparse regarding this condition. Outcome of treatment for infected non-union has been reported in only four reports. ${ }^{1-4}$ Only two of these describe results of infected nonunion exclusively in 1997 and 2009.1,4 We retrospectively reviewed a consecutive case series of infected non-union of humerus. We had 17 patients, out of which seven patients underwent staged debridement followed by intramedullary strut grafting, internal fixation and autogenous bone grafting. We reported these results. ${ }^{5}$ Remaining ten patients underwent debridement and Orthofix fixation. We review the rate of healing, time taken for healing, organisms, resolution of infection and complications.

\section{METHODS}

Ten consecutive series of patients with infected non-union of humerus shaft were treated between 2003 and 2011 by debridement and Orthofix external fixation. There were eight men and two women with mean age of 34 years (Range, 1750). All patients had discharging sinus at presentation and positive bacterial cultures. Seven patients had open fractures while the rest had closed fractures. Mid shaft of humerus was involved in eight patients, proximal third in one and distal third in one. Four patients presented with radial nerve palsy. Infection was detected at a mean 9.25 weeks from injury (range 2-24). Four patients had associated injury in the same limb. The average number of surgeries before presentation was 2 (Range, 1-4). All patients had preoperative evaluation including erythrocyte sedimentation rate, C-reactive protein, radiographs and clinical examination. Radiographs showed sequestrum in four patients (Figs. 1 and 2). Six patients had implant in situ. Multiple surgeons were involved in the treatment. At surgery thorough and radical debridement was done. All implants were removed. Deep tissue cultures were obtained (Table 1). Shortening was done in seven patients. All ten patients underwent Orthofix fixation using tapered pins $5.5 \mathrm{~mm}$ two above and two below the fracture site. Compression clamp was used in six patients to apply compression. Orthofix was applied laterally. Four patients underwent placement of antibiotic beads in addition. Post operatively patients were treated with intravenous antibiotics based on tissue culture till the wound healed (Table 1).Oral antibiotics was used for another six weeks when appropriate. All patients were encouraged shoulder and elbow range of movements after surgery. Once infection was under control as evidenced by clinical examination and normal C-reactive protein, bone grafting was considered based on clinical and radiological findings. Seven patients underwent autogenous bone grafting at an average of 8 weeks after external fixation (Range, 4-12). The discretion for bone grafting was with the treating surgeon. They were periodically followed up till the union of fracture and good functional recovery on an average 26 months.

\section{RESULTS}

There were eight men and two women. The average age was 34.5 (Range 17-50). The mode of injury in seven patients was road traffic accident, one fall from height, one bomb blast injury and one industrial accident. One patient had failure 2 of external fixation due to pin tract infections. He could not present himself for timely treatment. He had successful union with intramedullary strut grafting, internal fixation and bone grafting. The results are summarised in table 2 . Nine patients had positive cultures among them six had polymicrobial infection and they were treated with specific antibiotics (Table 1) Graph 1. The average follow-up was 26 months (Range, 3-72). All nine patients had healing of fracture at an average of four months (Range, 2-6) after index surgery (Figs. 3, 4 \& Graph 2). The average time between the external fixation and the bone grafting was eight weeks (Range, 4 -12). All the patients had resolution of infection at final follow up (Figs. 5). Out of four patients with radial nerve palsy two recovered Fig 6. Four patients had pin tract infections. No patient needed exchange of pins. Two patients had shoulder stiffness.

\section{Statistical Analysis}

Simple mean and average were calculated and there was no specific statistical analysis done. They are plotted in graph below.

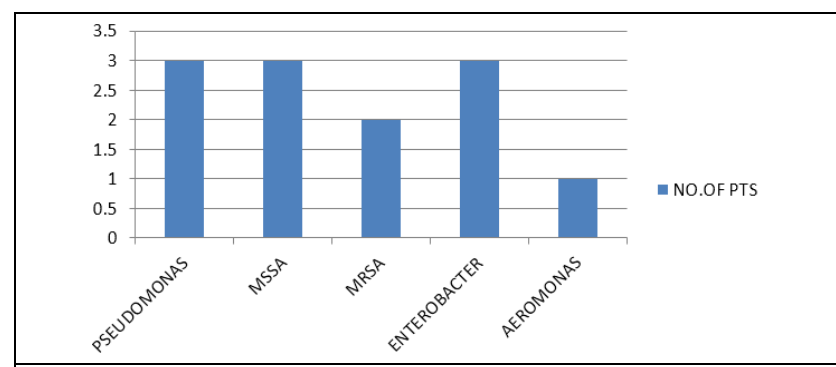

Graph 1. Microbiological Culture Pattern among the Study Patients
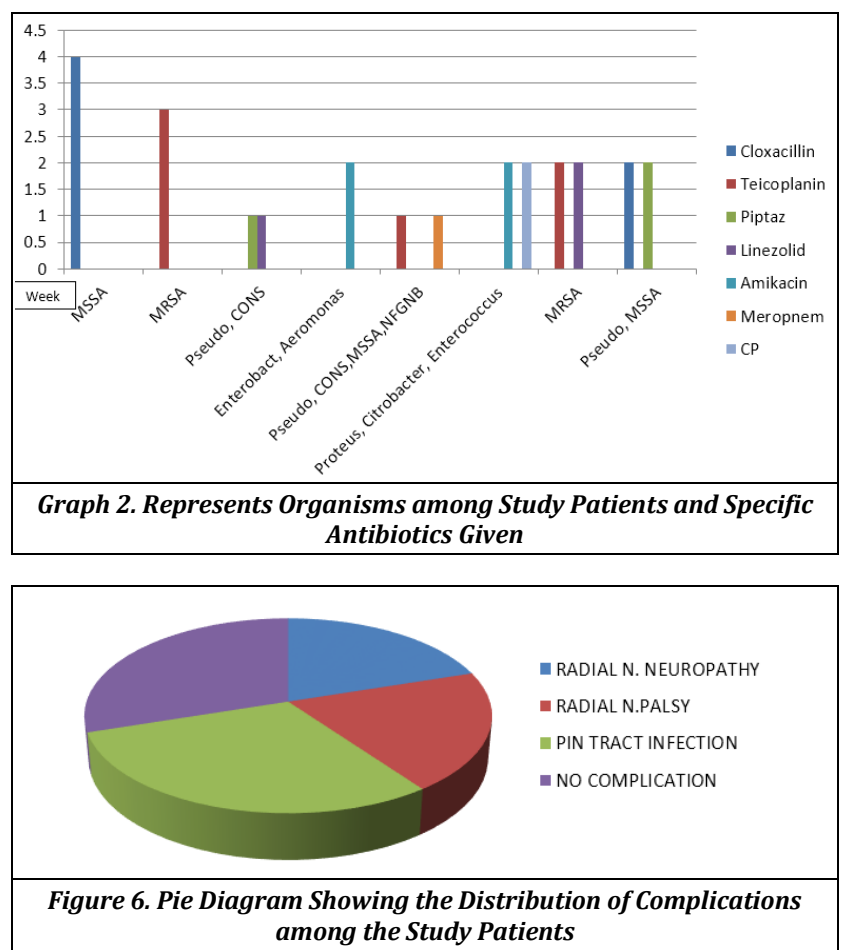

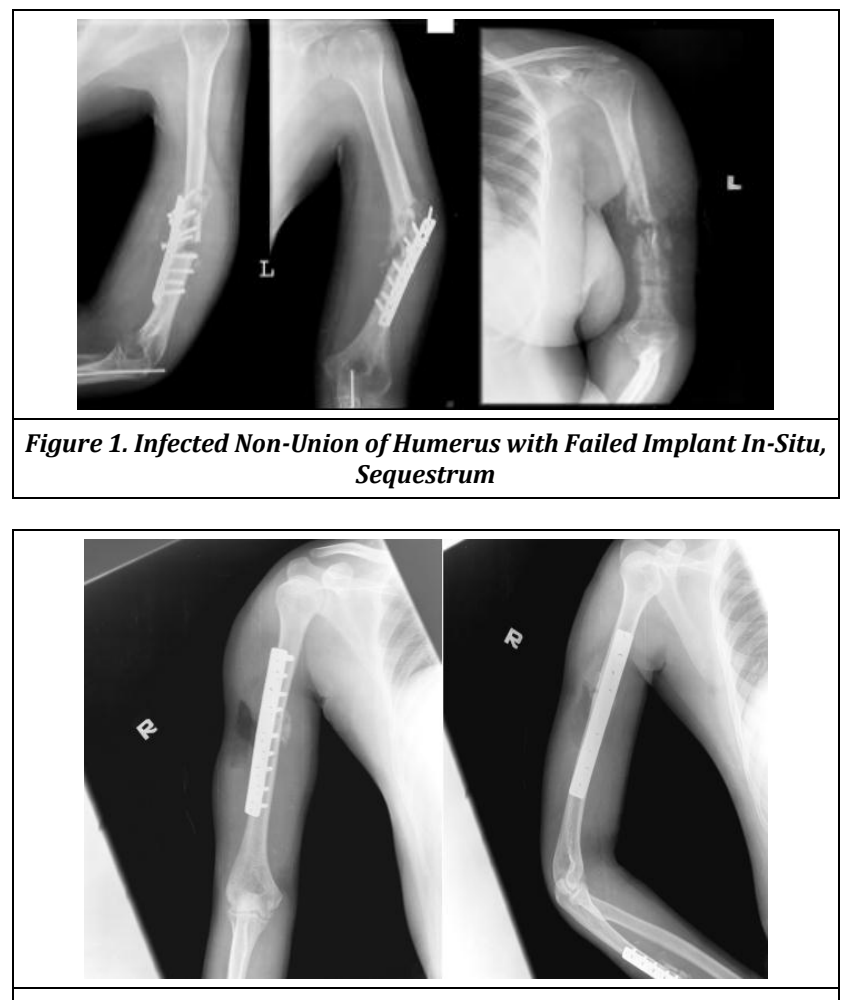

Figure 2. Infected Humeral Shaft Fracture with Implant In-Situ
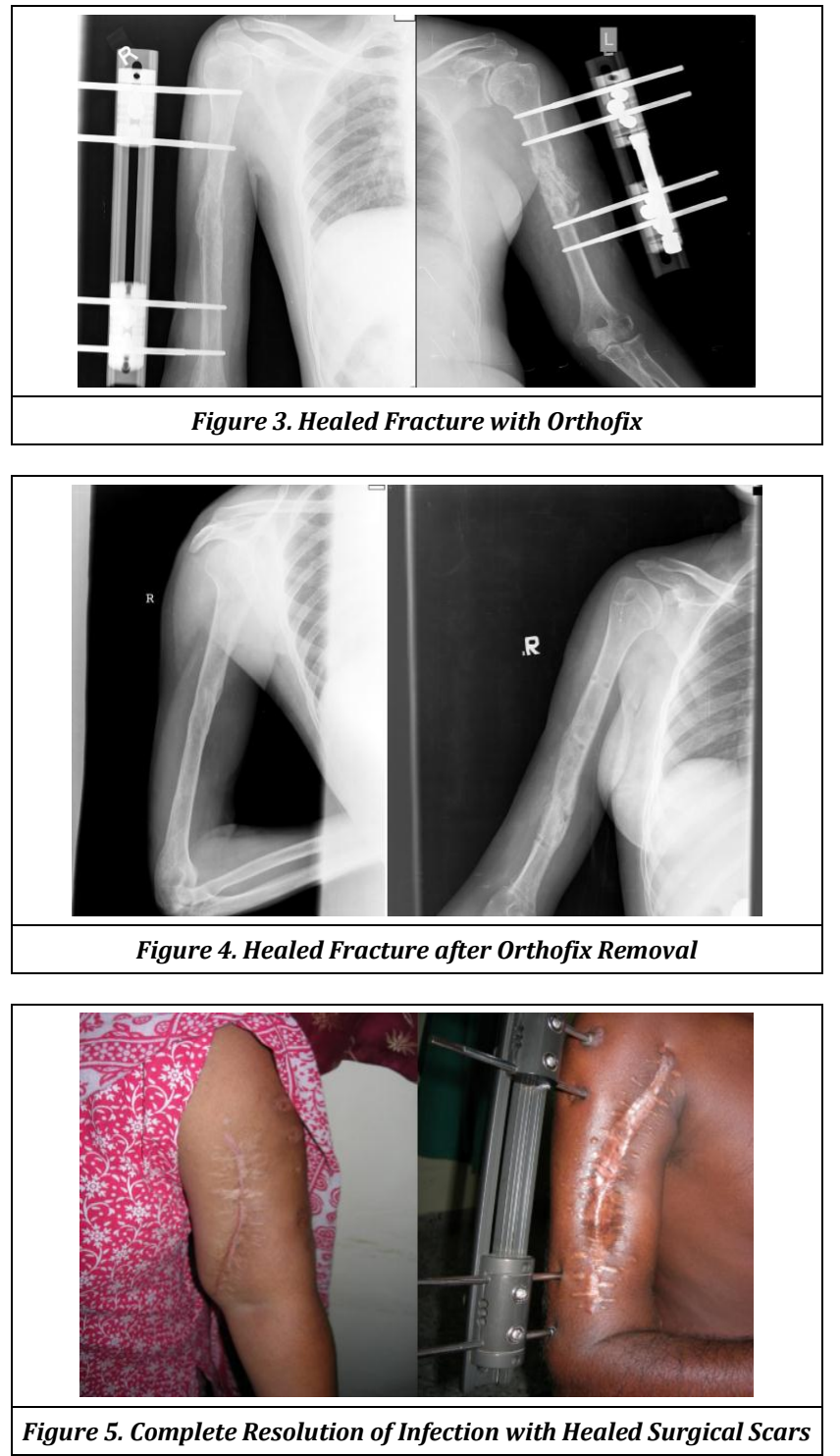

\begin{tabular}{|c|c|c|c|}
\hline Organism & Antibiotics & Duration & $\begin{array}{c}\text { Antibiotic } \\
\text { Beads }\end{array}$ \\
\hline MSSA & Cloxacillin & 4 weeks & \\
\hline MRSA & Teicoplanin & 3 weeks & Vancomycin \\
\hline $\begin{array}{c}\text { Pseudomonas, } \\
\text { Coagulase negative staph } \\
\end{array}$ & $\begin{array}{c}\text { Piperacillin, Tazobactam, } \\
\text { Linezolid }\end{array}$ & 1 week & Vancomycin \\
\hline Enterobacter, Aeromonas sp.H & \begin{tabular}{|c|} 
Amikacin \\
\end{tabular} & 2 weeks & \\
\hline $\begin{array}{c}\text { Pseudomonas aeruginosa, Coagulase } \\
\text { negative staph, Staphylococcus, } \\
\text { Non fermenting GNB } \\
\end{array}$ & Teicoplanin, Meropenem & 1 week & Vancomycin \\
\hline Proteus, Citrobacter, Enterococcus & $\begin{array}{l}\text { Amikacin, Crystallin } \\
\text { penicillin }\end{array}$ & 10 days & \\
\hline MRSA & Teicoplanin, Linezolid & 2 weeks & Teicoplanin \\
\hline $\begin{array}{c}\text { Pseudomonas aeruginosa, } \\
\text { Staphylococcus }\end{array}$ & $\begin{array}{c}\text { Piperacillin, Tazobactam, } \\
\text { Cloxacillin }\end{array}$ & 2 weeks & \\
\hline
\end{tabular}

Table 1. Organisms from Intra-Op Cultures, Appropriate Antibiotics and Duration, and Antibiotics used with Cement Beads

\begin{tabular}{|c|c|c|c|}
\hline Sl. No. & Time to Union & Bone Grafting & Complications \\
\hline 1 & 2.5 & Done & Nil \\
\hline 2 & 4 & Done & Pin tract infection \\
\hline 3 & 3 & No & Shoulder stiffness \\
\hline 4 & 4 & Done & Pin tract infection \\
\hline 5 & 2.5 & No & Pin tract infection \\
\hline 6 & 2.5 & Done & Pin tract infection \\
\hline 7 & 3 & Done & Shoulder stiffness \\
\hline 8 & 4 & No & \\
\hline 9 & 4 & Done & \\
\hline 10 & 4 & Done & Shoulder stiffness \\
\hline
\end{tabular}

Table 2. Time of Union, Number of Patients who Underwent Bone Grafting, and Complications

\begin{tabular}{|c|c|c|}
\hline Authors & $\begin{array}{c}\text { Number of Patients with } \\
\text { Infected Non-Union }\end{array}$ & Bone Grafting \\
\hline Kiran et al, 2010 & 6 & 0 \\
\hline Baissony et al, 2009 & 8 & 0 \\
\hline Lavini et al, 2001 & 4 & 3 \\
\hline Chen, Chao-Yu MD, 1997 & 14 & 14 \\
\hline \multicolumn{2}{|c|}{ Table 3. Literature Review on Infected Non-Union of } \\
Humerus Shaft Fractures \\
\hline
\end{tabular}

\section{DISCUSSION}

This is a retrospective review of a consecutive case series of patients who underwent debridement and external fixation for infected non-union of humerus with a good success rate. In all previous reports there was $100 \%$ healing with external fixation. In our series one patient had failure of external fixation, but subsequently healed with internal fixation. ${ }^{1-4,5,6,7}$

Table 3 summarises the result of previous studies. Except in the two studies by Baissony et al and Kiran et al which they did no bone grafting other authors have reported high rates of bone grafting. In our series also seven of ten patients underwent bone grafting. Our study period extends over eight years. In both studies without bone grafting, compression was used to achieve good results. The mean time to union compares favourably with other series.

Pseudomonas and MRSA was found in predominant number of patients in our series. This appears similar to Kiran et al results. We had polymicrobial infection in four patients. In our series average number of surgeries prior to presentation was 2 (Range 2-4). However thorough debridement ensured resolution of infection in all patients. As in other series the major complication was pin tract infections. Most of them subsided with antibiotics. Less number of patients had shoulder and elbow stiffness during follow up compared to preoperatively. This study has the limitation of any retrospective study. In addition, functional evaluation was not available. 


\section{CONCLUSIONS}

Infected non-union of humerus is an uncommon problem. Radical debridement, Orthofix fixation and bone grafting leads to high success rate. There is a high incidence of shoulder stiffness in this group of patients. Pin tract infection is a common complication.

\section{REFERENCES}

[1] Kiran M, Jee R. Ilizarov's method for treatment of nonunion of diaphyseal fractures of humerus. Indian J Orthop 2010;44(4):444-7.

[2] Bassiony AA, Almoatasem AM, Abdelhady AM, et al. Infected non-union of the humerus after failure of surgical treatment: management using the Orthofix external fixator. Ann Acad Med Singapore 2009;38(12):1090-4.

[3] Lavini F, Brivio RL, Pizzoli A, et al. Treatment of nonunion of the humerus using the Orthofix external fixator. Injury 2001;32 Suppl 4:SD35-40.

[4] Chen CY, Ueng SW, Shih CH. Staged management of infected humeral non-union. J Trauma 1997;43(5):7938.

[5] Gopisankar G, Justin AS, Nithyananth M, et al. Nonvascularised fibular graft as an intramedullary strut for infected non-union of the humerus. Journal of Orthopaedic Surgery (Hong Kong) 2011;19(3):341-5.

[6] Rose RE, Palmer WS. The Ilizarov method in infected non-union of long bones. West Indian Med J 2007;56(3):246-51.

[7] Brinker MR, O'Connor DP, Crouch CC, et al. Ilizarov treatment of infected nonunions of the distal humerus after failure of internal fixation: an outcomes study. J Orthop Trauma 2007;21(3):178-84. 